\title{
Desenvolvimento e povos indígenas: para uma crítica ao desenvolvimento sustentável
}

\author{
Development and indigenous peoples: for a critique of \\ sustainable development
}

\author{
Adriana de Oliveira Rocha ${ }^{1}$ \\ Antônio Hilário Aguilera Urquiza ${ }^{1}$
}

DOI: http://dx.doi.org/10.20435/tellus.vi44.746

\begin{abstract}
Resumo: O conceito de desenvolvimento sustentável consolidou-se em 1987, com o relatório Brundtland, e apesar dos vários desdobramentos teóricos trazidos até hoje, essa noção permanece não levando em conta o aporte empírico e científico dos povos indígenas. Ao produzirem os bens e serviços de que necessitam, vivendo suas próprias economias, os povos indígenas, e seus variados modos e meios de produção, são os que mais se aproximam do conceito de desenvolvimento sustentável. A sustentabilidade pressupõe a capacidade de não produzir danos ecológicos superiores à possibilidade de renovação dos recursos naturais. Coloca-se em xeque, no entanto, a noção de desenvolvimento nos moldes ocidentais, em relação às economias indígenas, as quais contemplam paradigmas endógenos, vinculados à cosmogonia e práticas culturais, entre outros elementos de distinção. Tais parâmetros são de difícil compreensão fora das sociedades indígenas, embora aproximem-se conceitualmente daquilo que se convencionou chamar de desenvolvimento sustentável. Incorporar a maneira de pensar dos povos indígenas pode trazer um ganho para as sociedades não indígenas, como o artigo se propõe a refletir. O presente texto é fruto da experiência e atuação profissional dos autores, assim como foi elaborado a partir de pesquisa bibliográfica e documental, com o objetivo de apresentar reflexão teórico-crítica acerca do tema do desenvolvimento.
\end{abstract}

Palavras-chave: povos indígenas; sustentabilidade; desenvolvimento; autonomia.

Abstract: The concept of sustainable development was consolidated in 1987 with the Brundtland report, and despite the various theoretical developments brought to date, this notion remains not taking into account the empirical and

${ }^{1}$ Universidade Federal do Mato Grosso do Sul (UFMS), Campo Grande, Mato Grosso do Sul, Brasil. 
scientific contribution of indigenous peoples. By producing the goods and services they need, living their own economies, indigenous peoples, and their varied modes and means of production, they are the ones that most closely approach the concept of sustainable development. Sustainability presupposes the ability not to produce ecological damage greater than the possibility of renewal of natural resources. However, the notion of development in western ways is in check, in relation to indigenous economies, which include endogenous paradigms, linked to cosmogony and cultural practices, among other elements of distinction. Such parameters are difficult to understand outside indigenous societies, although they are conceptually close to what has been called sustainable development. Incorporating the way of thinking of indigenous peoples can bring a gain to non-indigenous societies, as the article proposes to reflect. This text is the result of the experience and professional performance of the authors, as well as was elaborated from bibliographic and documentary research, with the objective of presenting theoretical-critical reflection on the theme of development.

Keywords: indigenous peoples; sustainability; development; self-determination.

Por isso que, quando aprendi sobre as vogais em Guarani, que é a palavra "y" a primeira coisa que Deus criou foi o rio, então depois vem "yvy" a terra, é uma corrente, uma ligação, ligado um no outro, não tem

separação. É uma célula, mas para nós a célula é essa: o "y", a água,

"yvy" a terra, "yvyra", as plantas, as plantas que a gente tem nas matas, e o "yvyru", ar. Então, se um deles acaba, acaba tudo, acaba tudo e não existe mais vida. (CHAPARRO; HARA; MACIEL, 2019).

\section{INTRODUÇÃO}

Desde a Declaração da Organização das Nações Unidas na Conferência Rio92, realizada no Brasil, o papel dos povos indígenas nas questões relacionadas com o desenvolvimento passou a ter relevância, ao menos formal, principalmente nos países onde esses povos estão em elevado número, ou onde há nichos ecológicos vitais para o planeta, como é o caso do Brasil, que detém grande parte (cerca de $60 \%)$ da maior floresta tropical do mundo.

Naquela conferência, seguida anos depois pela Rio +20 , avançou-se no conceito de desenvolvimento sustentável, cunhado em 1987, através do chamado relatório Brundtland. No documento preparado durante o encontro constam expressamente dois princípios dedicados à relação dos povos indígenas com os Estados nacionais, no que diz respeito ao desenvolvimento e à ecologia. 
No princípio $22^{2}$ constou o dever dos estados em reconhecer as identidades indígenas, suas culturas e seus interesses específicos, além de garantir a participação dos povos indígenas nos processos de desenvolvimento que os afetem, através da consulta livre, prévia e informada. Esse tipo de consulta está igualmente previsto na Convenção 169, da Organização Internacional do Trabalho, documento vinculante nos termos do direito internacional.

Já o princípio $23^{3}$, trouxe a ideia de descolonização para a pauta ambiental porquanto associa a retomada da gestão dos recursos naturais pelos povos indígenas ao fim dos processos de opressão, dominação e ocupação a que foram submetidos.

Importante assinalar que a Declaração Rio-92 foi antecedida pelos encontros que resultaram na Agenda 21, iniciada pela Organização das Nações Unidas (ONU, 1989) e cujas versões são atualizadas a cada nova conferência. Esse documento-guia da conferência possui um capítulo exclusivo (Capítulo 26) ${ }^{4}$ dedicado ao "reconhecimento e fortalecimento do papel das populações indígenas e suas comunidades" (ONU, 1989).

A movimentação iniciada entre 1989 e 1992, é um dos exemplos do esforço dos povos indígenas perante as organizações internacionais, com repercussão

2 Princípio 22: "As populações indígenas e suas comunidades, bem como outras comunidades locais, têm papel fundamental na gestão do meio ambiente e no desenvolvimento, em virtude de seus conhecimentos e práticas tradicionais. Os Estados devem reconhecer e apoiar de forma apropriada a identidade, cultura e interesses dessas populações e comunidades, bem como habilitá-las a participar efetivamente da promoção do desenvolvimento sustentável" (RAMID; RIBEIRO, 1992).

3 Princípio 23: O meio ambiente e os recursos naturais dos povos submetidos à opressão, dominação e ocupação devem ser protegidos (RAMID; RIBEIRO, 1992).

${ }^{4}$ Bases para la acción. 26.1. Las poblaciones indígenas y sus comunidades han establecido una relación histórica con sus tierras y suelen ser, en general, descendientes de los habitantes originales de esas tierras. En el contexto del presente capítulo, se sobreentiende que el término 'tierras' abarca el medio ambiente de las zonas que esas poblaciones ocupan tradicionalmente. [...]. Objetivos. 26.3. b) Establecer, cuando proceda, acuerdos para intensificar la participación de las poblaciones indígenas y sus comunidades en la formulación de políticas, leyes y programas relacionados con la ordenación de los recursos em el plano nacional y otros procesos que pudieran afectarles, así como para propiciar que formulen propuestas en favor de políticas y programas de esa índole; Medios de ejecución. b) Mecanismos jurídicos y administrativos. 26.8 Los gobiernos, en colaboración con las poblaciones indígenas afectadas, deberían incorporar los derechos y responsabilidades de las poblaciones indígenas y sus comunidades a la legislación de cada país, en la forma apropiada a su situación particular. Los países en desarrollo podrán requerir asistencia técnica para llevar a cabo esas actividades (ONU, 1989). 
junto aos governos locais, para ver seus conceitos sobre economia, desenvolvimento e ecologia contemplados nos planejamentos domésticos e nas iniciativas internacionais nesses campos. Em que pese os documentos internacionais fazerem menção aos povos indígenas, parece não ter havido grandes avanços no que diz respeito à incorporação efetiva dos conceitos autóctones sobre desenvolvimento nas práticas econômicas mundo afora.

O objetivo do presente texto é, pois, indagar se os regimes econômicos vigentes não estariam criando ideias, como a do desenvolvimento sustentável, tão somente como forma de manter-se infensos à incorporação, ou proteção, de práticas produtivas diversificadas e multiculturais, como são a dos povos indígenas. A fim de responder essa pergunta, o trabalho irá se valer de autores associados à Teoria Crítica e ao Pós-Desenvolvimento para colocar em xeque a própria noção de desenvolvimento sustentável.

Assim, o artigo irá se estruturar em três partes, sendo que a primeira irá explicar o método de análise denominado Teoria Crítica, provindo da escola de filosofia de Frankfurt, e como esta teoria tem examinado o conceito de desenvolvimento sustentável. Além disso, se dará um panorama sobre os fatos históricos que desembocaram no uso corrente do termo sustentabilidade associado às teorias do desenvolvimento, entre elas a do pós-desenvolvimento.

Na segunda parte será feito um apanhado dos estudos sobre etnodesenvolvimento, e no que eles têm colaborado com a crítica ao conceito de desenvolvimento. Os estudos sobre etnodesenvolvimento propõem uma ação indigenista que proporcione a apropriação mútua, entre indígenas e não indígenas, das diferentes concepções de mundo natural, práticas medicinais e tecnologias adaptativas.

Na terceira e última parte irá se exemplificar algumas experiências de desenvolvimento em terras indígenas, e como elas confirmariam a premissa do artigo, de que as atuais abordagens, tanto de desenvolvimento, quanto de desenvolvimento sustentável, não abarcam suficientemente as perspectivas indígenas, quanto aos modos de produção, de criar e fazer, os quais se relacionam com as economias indígenas.

Nesse sentido, visualizamos o tema da relação entre estes povos ancestrais e o desenvolvimento como uma realidade que atravessa a história ameríndia e 
dos Estados Nacionais, particularmente após a expansão do mercado capitalista e o modelo das monoculturas agroexportadoras.

Essa relação assimétrica marca as vidas dessas sociedades, uma vez que compromete todo um processo de produção e reprodução cultural e de cosmologia. Assim, conforme indicado por este dossiê, pretendemos trazer a reflexão para o centro das diversas discussões que envolvem as realidades das sociedades indígenas, com implicações diretas para o conjunto da sociedade nacional e da existência planetária.

Em termos metodológicos, o texto é fruto da experiência e atuação profissional dos autores, assim como foi elaborado a partir de pesquisa bibliográfica e documental, com o objetivo de apresentar reflexão teórico-crítica acerca dos povos indígenas e os conceitos de desenvolvimento e sustentabilidade.

\section{TEORIAS DO DESENVOLVIMENTO E O DESENVOLVIMENTO SUSTENTÁVEL}

$\mathrm{Na}$ economia, o conceito de desenvolvimento iniciou por ser estudado entre autores que vão de Adam Smith (1776), Thomas Malthus (1798), David Ricardo (1817) a Karl Marx (1867), e sempre foi abordado como um fenômeno importante para a consolidação do sistema capitalista (SANTOS, 2012, p. 47):

[...] porém, é na década de 1940, que o desenvolvimento recebe o status de objeto de pesquisa científica com o surgimento da Economia do Desenvolvimento. Com ela, é construído todo um arcabouço teórico e metodológico para descrever e promover o desenvolvimento como algo próximo a uma sociedade industrial, urbana e detentora de riqueza, por meio de acúmulo de renda monetária.

A economia do desenvolvimento tornou-se então uma categoria destacada dos estudos sobre economia, tomando a partir daí um assento próprio, inobstante da sobrevalorização descrita em Gómez (2002, n.p.):

Apenas nos últimos cinquenta anos vem se trabalhando com a ideia de desenvolvimento. Não se trata, portanto, de uma categoria de profundo conteúdo histórico, tampouco de uma categoria ontologicamente atrelada ao devir da sociedade, como poderia deduzir-se da consideração e às vezes, veneração, com que esta ideia é apresentada e trabalhada. 
No campo da Teoria Crítica ${ }^{5}$, abordado por Vizeu, Meneghetti e Seifert (2012, p. 570), faz-se a descrição do conceito de desenvolvimento sustentável que "[...] se pretende orientador de esforços coletivos tanto de Estados e entidades 'governamentais nacionais e supranacionais, como para organizações não governamentais e empresas preocupadas com a questão ecológica'”.

Ou seja, o próprio capitalismo, na tentativa de remediar as consequências de uma ideologia de produção e consumo "ilimitados", favorece a criação do conceito de sustentabilidade, como uma forma de apontar para a possibilidade em equilibrar os efeitos nefastos de seu modelo predador da natureza.

Para os teóricos críticos, porém, a ideia de desenvolvimento sustentável "emerge de condições particulares de contradição do sistema capitalista, uma vez que, no surgimento da ideia de sustentabilidade, destacam-se os efeitos nocivos que o avanço desse sistema trouxe para o planeta, particularmente, para a questão ecológica." (VIZEU; MENEGUETTI; SEIFERT, 2012, p. 570). O desenvolvimento sustentável se fundamentaria, assim, segundo esses autores:

[...] em uma concepção conciliatória com o capitalismo, que deixa transparecer uma ambígua relação entre as condições históricas de sua emergência como ideia pretensamente reparadora da atual crise socioambiental e de seu real sentido de reforço da lógica do capital. De forma muito clara, essa ambiguidade assinala o caráter ideológico que o conceito apresenta. (VIZEU; MENEGUETTI; SEIFERT, 2012, p. 570).

A questão trazida pela teoria crítica diz respeito a colocar em questão o sistema de produção capitalista, já que os agravos ao meio ambiente e a desigualdade econômica são gerados no seu interior, havendo no emergir do conceito de desenvolvimento sustentável uma falsa noção de conciliação entre o capitalismo e a questão ecológica. Para essa corrente, a adoção do adjetivo "sustentável" tem por principal intento:

\footnotetext{
5 “No texto 'Teoria Tradicional e Teoria Crítica', Horkheimer (1991a) apresenta os fundamentos da Teoria Crítica. Segundo ele, "a teoria crítica não se deixa enganar pela aparência, isto é, pela ilusão fomentada meticulosamente nas ciências sociais, de que propriedade e lucro não desempenhariam mais o papel decisivo" (HORKHEIMER, 1991a, p. 64). Seus fundamentos estão embasados na tendência de o capitalismo instituir-se como sistema econômico totalitário, influenciando todas as dimensões da vida social e estendendo suas análises para o campo da ciência, que considera ser uma força produtiva a serviço dos interesses dos grupos dominantes" (HORKHEIMER, 1991 apud VIZEU; MENEGUETTI; SEIFERT, 2012, p. 570).
} 
[...] dissipar a névoa que desvia a atenção sobre os problemas reais e cada vez mais agudos da prática econômica capitalista. [...] A teoria crítica tem como princípio revelar as contradições, desvelando o real e mostrando que a aparência quase sempre não corresponde com a essência. (VIZEU; MENEGHETTI; SEIFERT, 2012, p. 570).

Escamoteia-se, ademais, a questão da posição das classes nesse tipo de conceito, uma vez que empresas e estados articulam ações e planejamento com interesses, no mínimo heterogêneos, quando não, "contraditórios", como por um lado, "a busca do lucro por parte de empresários", a exploração dos recursos naturais e o consumo ilimitado ("a lógica do mercado"), e a adesão por outro, ao tema da "preservação da natureza" e inclusive a defesa da justiça social Fica assim, subsumido, sem problematizar, à lógica do capitalismo, que é a exploração da força de trabalho de um grupo social por outro (VIZEU; MENEGHETTI; SEIFERT, 2012).

Ainda no campo da teoria crítica, Gómez (2002, n. p.) adverte sobre a subordinação estrutural do trabalho ao capital. Ainda que os adjetivos sofram mudanças ao longo das décadas, com a substituição da teoria do desenvolvimento irrestrito por teorias que convergem para o chamado desenvolvimento sustentável, "a estrutura de dominação se mantém":

Se o desenvolvimento, como "obrigação" para os países "subdesenvolvidos", mostrava limites intransponíveis e "legitimava" uma situação de dependência, o "novo" desenvolvimento com base local continua, no fundamental, a repetir as mazelas que acompanham o movimento de reprodução capitalista, depois de redimensionar seu campo de implementação e de adequá-lo às ideias da democracia formal vigente. Os adjetivos como humano, solidário ou sustentável, associados ao desenvolvimento local, são tentativas de harmonizar a lógica destrutiva do capital em relação ao gênero humano. Uma tentativa fadada ao fracasso. Por baixo da potenciação dos recursos endógenos, do fomento à participação da sociedade civil na construção do desenvolvimento e da inter-relação harmônica com o território local, subjaz à lógica da rentabilidade, da concorrência e do controle social. (GÓMEZ, 2002, s.p.).

Entre as compreensões liberais sobre desenvolvimento, a ideia de capacidades em Amartya Sen (2000, p. 17) descreve o desenvolvimento como "um processo de expansão das liberdades reais que as pessoas desfrutam". Sen realizou a crítica sobre indicadores de desenvolvimento que não levavam em conta elementos como as capacidades humanas. Na perspectiva do autor indiano, as 
capacidades humanas permaneceriam obstruídas nos países com baixo desenvolvimento, impedidas assim de serem empregadas para o alcance de um desejável bem-estar de todos.

Ele faz a crítica das "visões mais restritas de desenvolvimento, como as que identificam desenvolvimento com crescimento do Produto Nacional Bruto (PNB), aumento de rendas pessoais, industrialização, avanço tecnológico ou modernização social" (SEN, 2000, p. 17). Ao fazê-lo elaborou um novo índice de medição do desenvolvimento chamado Índice de Desenvolvimento Humano $(\mathrm{IDH})^{6}$, largamente empregado desde então.

A tomar-se por esse índice, pode-se entrever distinções expressivas para o conceito de desenvolvimento, no que tange às várias populações do mundo. O lugar de fala de Sen, nascido em um país não ocidental, influenciou seu pensamento na análise de inúmeras situações relacionadas com sua origem. As avaliações até então empregadas não se amoldavam aos países chamados de subdesenvolvidos ou terceiro-mundistas:

Na visão de Sen, para pensar a equidade social, é necessário inserir nos debates a questão da diversidade humana, além de reconhecer os valores e as concepções de vida daqueles que seriam "alvos" dos "projetos" de desenvolvimento. $O$ autor questiona as concepções de desenvolvimento restritas ao crescimento do Produto Interno Bruto e ao aumento das rendas pessoais, ou de qualquer outra avaliação que tenha como critério único indicadores monetários. A vida das pessoas é a finalidade última, sendo a produção e a prosperidade meros meios para atingi-la. O objetivo é a liberdade, a fim de que os indivíduos não sofram privação de capacidades e estejam livres para viver do modo que preferirem; ou seja, a fim de que os indivíduos possam agir para ir ao encontro das mudanças a eles propiciadas, de acordo com seus valores e objetivos. (FREITAS et al., 2016, p. 51).

\footnotetext{
6 "No que tange às principais implicações do seu trabalho, cumpre mencionar que, em 1993, juntamente com Mahbudul Haq, economista paquistanês, Sen propôs o Índice de Desenvolvimento Humano (IDH), o qual vem sendo aplicado desde então pelo Programa das Nações Unidas para o Desenvolvimento (PNUD) em seu relatório anual, e se tornou uma das principais medidas comparativas de desenvolvimento utilizadas por inúmeras organizações em todo o mundo. 0 IDH é composto de dados relativos à expectativa de vida ao nascer, à educação e ao PIB per capita. Ele possibilita comparar a situação de diferentes países, regiões, estados e municípios em dado momento, ou em séries históricas, com vistas a analisar os avanços ao longo do tempo. " (FREITAS et al. 2016, p. 53).
} 
Nessa concepção de Sen (2000), quando coloca a ênfase na liberdade, certamente defende a igualdade de condições de todas as pessoas ao nascerem. Não basta "nascer livres", mas sim com as mesmas condições de desenvolver suas capacidades, na realização de seus sonhos e metas, conforme seus valores e princípios:

[...] a abordagem seniana deita um olhar novo sobre o desenvolvimento, que não o estritamente econômico. A noção de desenvolvimento proposta por Amartya Sen sustenta que este somente pode ser alcançado quando os indivíduos dispõem dos "meios" pelos quais podem realizar os "fins" que almejam, ultrapassando obstáculos preexistentes que condicionem ou restrinjam a liberdade de escolha. Segundo o autor, os benefícios do crescimento ampliam as capacidades humanas - o conjunto das coisas que as pessoas podem ser ou fazer na vida. Quando se dá a expansão dessas capacidades, as pessoas têm as condições necessárias para fazer suas escoIhas e alcançar a vida que realmente desejam. (FREITAS et al. 2016, p. 53).

Os estudos de Sen, sob a perspectiva liberal, e visando à redução de desigualdades, são secundados por aqueles preocupados com a questão ecológica. Foi a partir dos anos 1970 que o alarme ecológico ganhou destaque no debate político internacional, reforçado por estudos como os de Rachel Carson, de 1962, que demonstrou os efeitos danosos do Dicloro-Difenil-Tricloroetano (DDT) sobre animais e seres humanos, no icônico "Primavera Silenciosa".

De tais estudos, de início dedicados ao meio ambiente, avançou-se para a discussão da sustentabilidade em si. Ainda que tivesse surgido anteriormente à década de 1990, com o relatório Brundtland, de 1987, de sua vez, inspirado no Relatório Meadows (1972) ${ }^{7}$, coordenado pela cientista Dana Meadows do Massachussets Institute of Technology (MIT), o debate se iniciou verdadeiramente em fins dos anos 1980.

O relatório Meadows havia sido exibido em 1972, em reunião do Clube de Roma ${ }^{8}$, derivando de um estudo acadêmico denominado "Limites do crescimento",

\footnotetext{
7 "Com base em modelos matemáticos desenvolvidos por pesquisadores do Massachusetts Institute of Technology (MIT), esses esforços procuravam demonstrar que o planeta não suportaria o crescimento econômico e populacional ilimitado com base em recursos naturais finitos." (VIZEU; MENEGHETTI; SEIFERT, 2012)

8 "Todo esse fervor fez com que, em 1968, fosse criado o Clube de Roma, uma organização formada por intelectuais e estudiosos, cujo principal objetivo era discutir assuntos relacionados à
} 
mas já apresentava um ponto de vista sistêmico (e não só ambientalista) sobre problemas globais: distribuição de renda, êxodo rural, exploração abusiva de recursos naturais etc. (VARGAS; ARANDA; RANDOMSKY, 2016, p. 103).

Neste relatório, já constatamos a centralidade da crítica ao modelo de "desenvolvimento" e suas consequências globais. Três meses depois foi realizada uma conferência das Nações Unidas sobre Meio Ambiente em Estocolmo "onde, pela primeira vez, se debatem temas centrais relativos ao crescimento econômico, desenvolvimento e proteção ambiental (VARGAS; ARANDA; RANDOMSKY, 2016, p. 101).

Assim, em abril de 1987, a Comissão Brundtland trouxe o conceito de desenvolvimento sustentável para o discurso público, resumido em uma frase que se tornou amplamente conhecida: "O desenvolvimento sustentável é o desenvolvimento que encontra as necessidades atuais sem comprometer a habilidade das futuras gerações de atender suas próprias necessidades" (ONU, 1987).

A escolha da médica, mestre em Saúde Pública e ex-Primeira Ministra da Noruega, Gro Harlem Brundtland, pelo Secretário-Geral da ONU, para presidir a Comissão Mundial sobre o Meio Ambiente e Desenvolvimento, foi tida como "natural para este papel, à medida que sua visão da saúde ultrapassa as barreiras do mundo médico para os assuntos ambientais e de desenvolvimento humano" (ONU, 1989). O termo "sustentabilidade" passou, desde então, a ter uso corrente:

As questões de desenvolvimento e meio ambiente aparecem intimamente relacionadas entre si: alguns modos de desenvolvimento prejudicariam o meio ambiente, e isso poderia obstar o próprio desenvolvimento. [...] O Relatório conclui que não existe outra solução a não ser a instauração de um desenvolvimento sustentado, caracterizado como aquele capaz de garantir as necessidades das gerações futuras. (VARGAS; ARANDA; RANDOMSKY, 2016, p. 101-2).

A proposta do Relatório Brundtland é de compatibilizar o crescimento econômico com a questão ecológica. A semente teórica e de pesquisa lançada pelo Relatório Meadows foi confirmada. Não escapa, porém, à teoria crítica, que "na

política, economia, meio ambiente e desenvolvimento sustentável. Pode-se dizer que seu maior produto foi publicado na reunião de 1972, quando foi apresentado um relatório intitulado 'Os Limites do Crescimento'" (OLIVEIRA et al., 2012, p. 70). 
contramão do que fora proposto pelo Relatório Meadows (1972), de reduzir a zero o patamar do crescimento econômico, o Relatório Brundtland silencia sobre o tema" (VARGAS; ARANDA; RANDOMSKY, 2016, p. 102).

Neste embate, fica visível, a percepção da não sustentabilidade do modelo até então empregado de crescimento-desenvolvimento e busca-se, pelo menos no campo "semântico", uma solução intermediária, no sentido de compatibilizar elementos até então, incompatíveis.

De fato, em menos de cinco décadas (1972-2020), o novo viés emprestado aos estudos sobre desenvolvimento, vem sendo questionado, por autores que começam a ver contradições entre os termos "desenvolvimento" e "sustentável", entre eles o francês Serge Latouche (2009, p. 8-9), para quem "o desenvolvimento, conceito etnocêntrico e etnocidário, se impôs pela sedução, combinada com a violência da colonização e do imperialismo". De acordo com Serge Latouche:

O decrescimento per se não é realmente uma alternativa concreta. É, antes de tudo, uma matriz que autoriza alternativas. Trata-se, portanto, de uma proposta necessária para reabrir o espaço da inventividade e da criatividade do imaginário, bloqueado pelo totalitarismo economicista, desenvolvimentista e progressista. [...]. Uma política de decrescimento poderia consistir, em primeiro lugar, na redução ou ainda na supressão de externalidades negativas do crescimento, as quais vão desde gastos com publicidade até medicamentos contra o stress. O questionamento do considerável volume de deslocamentos de pessoas e mercadorias sobre o Planeta, com o correspondente impacto negativo sobre o meio ambiente, (e portanto, uma re-regionalização da economia), da não menos considerável publicidade barulhenta e muitas vezes nefasta e por fim, da obsolescência dos produtos e aparelhos descartáveis, sem outra justificativa a não ser a de fazer andar cada vez mais rápido a mega máquina funcional, são reservas importantes de decrescimento do consumo material. Sem falar dos enormes pressupostos militares... Para pensar sobre a transição podemos imaginar, além disso, em um programa completo, por exemplo: a) voltar aos anos 1960 - $1970 \mathrm{com}$ uma marca ecológica igual ou inferior a um planeta; b) re-regionalizar as atividades; 3) adotar a planificação de uma volta a agricultura camponesa; c) implodir a produção de bens relacionais etc. (LATOUCHE, 2006, p. 10).

A exemplo da proposta latouchiana do decrescimento, os estudos denominados "pós-desenvolvimento" visam, já no século 21, a colocar em questão a ideia de desenvolvimento como um dado social posto: 
Atualmente, o discurso do desenvolvimento pode ser compreendido como uma crença social, uma vez que aparece como uma certeza coletiva que não é colocada à prova (RIST, 2008). A maior parte das pessoas acredita que o desenvolvimento é algo bom e necessário, sem fazer um exame minucioso sobre as consequências das políticas e práticas a ele relacionadas. O mesmo se diga a respeito da noção de progresso, tão disseminada e tão pouco questionada quanto à sua validade histórica para explicar a mudança social (DUPAS, 2007). [...] Apesar da hegemonia exercida desde o fim da Segunda Guerra Mundial pelas políticas e programas de desenvolvimento, muitos pesquisadores (RIST, 2008; ESCOBAR, 2007; CRUSH, 1995; ESTEVA, 1992) passaram, a partir dos anos 80 , a produzir estudos críticos sobre os processos de desenvolvimento. Ainda que apresentem orientações teóricas distintas, esses autores têm em comum o mérito de demonstrarem como o desenvolvimento é um discurso historicamente construído que, sob pretexto de melhorar a vida de comunidades pobres, tem causado intervenções com impactos negativos para as populações. (FREITAS; CRUZ; RADOMSKY, 2016, p. 93).

Com efeito, ao se tomar, por exemplo, o protocolo de consulta e consentimento Wajãpi (REDE DE COOPERAÇÃO AMAZÔNICA [RCA], 2015), um povo indígena tupi, com existência na Amazônia brasileira, pode-se avaliar uma possível reflexão daquele povo sobre o que significaria desenvolvimento para si mesmo. Indagados sobre seu modo de vida, os Wajãpi respondem:

Nós Wajãpi temos um modo de vida muito diferente de vocês. Nós temos uma cultura muito forte e não esquecemos nenhuma coisa. Nós sabemos nos pintar, sabemos cantar, sabemos criar nossos filhos, educar nossas crianças e cuidar do nosso corpo. Nós Wajãpi temos um modo de morar muito diferente dos não índios. Desde muito tempo atrás nós estamos sempre mudando de lugar. Sabemos procurar lugares bons para morar, onde o terreno é bom, a terra é boa, é bom de fazer a roça. Onde é bom de caça e bom de peixe. Nós não moramos sempre no mesmo lugar. (RCA, 2015).

Os pesquisadores do pós-desenvolvimento refutam a tese de que o desenvolvimento seja o único meio para se atingir uma melhora nas condições de vida, ou redução das desigualdades, e buscam dar visibilidade a outras realidades, experimentadas por povos tradicionais e por movimentos sociais:

A discussão teórica sobre o desenvolvimento e as políticas e programas implementados pelos Estados e governos parte geralmente da premissa da naturalidade do desenvolvimento, tratando-o como um processo 
inquestionável. Para essa visão progressista simplória, o desenvolvimento é um processo com o qual a humanidade convive há muito tempo, ou pelo menos desde a Revolução Industrial. Um exercício reflexivo válido consiste em aventar outras possibilidades, explorar modos distintos de conceber a mudança social e o desenvolvimento. Será possível pensar a vida em sociedade fora do eixo balizador do desenvolvimento? Uma sociedade em que não exista o conceito de desenvolvimento? Será razoável dizer que poderíamos viver em uma sociedade que não se represente em termos classificatórios, tais como "desenvolvido" versus "subdesenvolvido"? Este capítulo tem por finalidade realizar um balanço teórico sobre o pós-desenvolvimento perspectiva recentemente surgida nas ciências sociais -, examinando suas características principais, apresentando alguns de seus principais propositores e analisando em que medida esta possibilidade interpretativa pode ser instrutiva para os estudos sobre o desenvolvimento. (FREITAS; CRUZ; RADOMSKY, 2016, p. 93).

No debate do pós-desenvolvimento se incluiriam:

[...] elementos até então pouco discutidos por pesquisadores da área: a preservação ambiental e a diversidade cultural dos povos, bem como o desejo das pessoas de viverem sem demasiada preocupação com o aumento da produtividade e com o crescimento econômico. (FREITAS; CRUZ; RADOMSKY, 2016, p. 97).

Advertem, porém os autores que os estudos intitulados de "pós-desenvolvimento" não se confundem:

[...] com outras importantes críticas endereçadas ao modelo convencional de desenvolvimento tais como o desenvolvimento sustentável, a abordagem multidimensional que se diversificou a partir do Índice de Desenvolvimento Humano (IDH) da ONU e a abordagem das capacitações proposta por Amartya Sen. Os autores do pós-desenvolvimento rejeitam a manutenção de qualquer noção de desenvolvimento. Eles não estão em busca de desenvolvimentos alternativos, mas de alternativas ao desenvolvimento. (FREITAS; CRUZ; RADOMSKY, 2016, p. 98-9).

Os pesquisadores do pós-desenvolvimento alertam para o risco de abordagens meramente economicistas que reduziriam a desigualdade a uma questão produtivista, com foco na mensuração da produção e da renda. Tais abordagens levariam ao desprezo pela diversidade de práticas produtivas, resultando, por exemplo, em:

[...] políticas de modernização da agricultura a uma tentativa de homogeneização, não apenas dos sistemas de cultivo e criação, mas do conjunto 
das características que definem o mundo rural, sempre tomando por base um ideal 'moderno-industrial' frequentemente inadequado às expectativas de vida de inúmeros agricultores e grupos sociais, sobretudo das chamadas "comunidades tradicionais". (FREITAS et al., 2016, p. 58).

Os povos indígenas frequentemente são descritos como pouco produtivos, praticantes de uma agricultura de subsistência, com tendência a ser superada com técnicas modernas, porquanto "primitiva" e de baixo "rendimento". Os autores da corrente do pós-desenvolvimento discordariam dessa avaliação, uma vez que propõem o reconhecimento da diversidade:

Expor, por exemplo, diferentes agricultores às mesmas condições de mercado e políticas públicas significaria reproduzir elementos da desigualdade-acesso à terra, ao crédito e aos canais de comercialização, por exemplo - que comprometem a reprodução de inúmeros grupos e unidades de produção no meio rural. O desafio consiste, pelo contrário, em garantir o acesso aos meios, a fim de que esses agricultores tenham condições de constituir o tipo de vida que julguem relevantes, mantendo os aspectos essenciais - materiais e simbólicos - que definem sua identidade social, a qual é necessariamente diversa da de outros grupos. (FREITAS et al. 2016, p. 58).

Na próxima seção nos dedicaremos a fazer breve apanhado do conceito de etnodesenvolvimento, de 1981, o qual antecipou o relatório Bruntland, de 1987, e segue instigando o pensamento de todos quantos trabalham com o tema do desenvolvimento e povos indígenas.

\section{ETNODESENVOLVIMENTO COMO CAMINHO PRÓPRIO AOS POVOS INDÍGENAS}

No contexto da redemocratização do país, os povos indígenas brasileiros angariaram um capítulo da carta constitucional, contendo dois dispositivos que expressam o regramento e principiologia a ser observada pela sociedade nacional quanto à convivência com as sociedades indígenas (Constituição Federal 1988, art. 231 e art. 232). Esse feito é altamente relevante do ponto de vista jurídico e político, uma vez que durante quase 500 anos o Estado brasileiro se recusou a reconhecer a diversidade cultural e linguística dos povos indígenas e, por acréscimo, pouco fez em relação aos seus direitos originários aos territórios tradicionais. 
Mesmo assim, apesar das tentativas de assimilação e negação das identidades indígenas, ainda subsistem no país, segundo dados do IBGE (2010), ao redor de 300 etnias, com suas particularidades culturais, históricas, territoriais e visão de mundo. Esses povos receberam com esperança a Constituição Federal, pois pela primeira vez, o Estado ao mesmo tempo em que reconheceu sua diversidade, assinalou para o reconhecimento dos direitos fundamentais ao território (e ao desenvolvimento), na medida em que distingue aos povos indígenas o direito à organização social e à reprodução física e cultural (AGUILERA URQUIZA, 2016).

A situação econômica e jurídica da cerca das mais de duas centenas de povos indígenas no Brasil, cujas terras sob seu usufruto, e de propriedade da União, somadas correspondem a cerca de 13\% (treze por cento) do território nacional, pode ser resumida na última década, a

[...] por um lado, povos territorializados, juridicamente reconhecidos como detentores de um patrimônio sociocultural inestimável, de bens materiais sob a forma de terras e recursos naturais, de conhecimentos sobre o meio ambiente; por outro, povos que, por força dos mesmos processos de territorialização que conduziram a essa condição, vivem com frequência em situação de extrema penúria, sem recursos para geração de renda suficiente que lhes dê condições de suportar o crescimento vegetativo que enfrentam. (SOUZA LIMA, 2010, p. 22).

A questão do desenvolvimento relacionada com os povos indígenas vinha sendo tratada academicamente, e na forma de ativismo, sendo emblemática a realização da reunião de peritos sobre etnodesenvolvimento e etnocídio na América Latina, em 1981, na Costa Rica, quando foi formulada a proposta do etnodesenvolvimento pelo antropólogo mexicano Rodolfo Stavenhagem (SOUZA LIMA, 2010, p. 34).

O conceito de etnodesenvolvimento proposto pelo mexicano viria ao encontro da crítica dos estudiosos aos impactos das políticas desenvolvimentistas sobre os povos indígenas latino-americanos, tomando o caminho oposto, qual seja, o de contemplar "o diferencial sociocultural de uma sociedade, ou seja, sua etnicidade" (AZANHA, 2002, p. 31):

Na definição de Stavenhagem, 'o etnodesenvolvimento significa que uma etnia, autóctone, tribal ou outra, detém o controle sobre suas próprias terras, seus recursos, sua organização social e sua cultura, e é livre para negociar 
com o Estado o estabelecimento de relações segundo seus interesses'. (STAVENHAGEM, 1984 apud AZANHA, 2002).

Interpretando o conceito, e o transportando para a realidade brasileira, Azanha (2002, p. 32), estabelece alguns parâmetros, os quais, se preenchidos, poderiam indicar que o desenvolvimento passaria enfim a respeitar a visão dessas sociedades sobre suas próprias economias e organização social:

Nesses termos, o 'etnodesenvolvimento', quando referido às sociedades indígenas brasileiras, envolveria os seguintes indicadores: a) aumento populacional, com segurança alimentar plenamente atingida; b) aumento do nível de escolaridade, na 'língua' ou no português, dos jovens aldeados; c) procura pelos bens dos 'brancos' plenamente satisfeita por meio de recursos próprios gerados internamente de forma não predatória, com relativa independência das determinações externas do mercado na captação de recursos financeiros; e d) pleno domínio das relações com o Estado e agências de governo, a ponto de a sociedade indígena definir essas relações, impondo o modo como deverão ser estabelecidas. (AZANHA, 2002, p. 32).

Outro autor que desenvolve a ideia do etnodesenvolvimento, Little (2002) dedica um artigo a fazer entender termos como intercientificidade, etnometodologia e etnoecologia. Segundo ele "[...] se a relação entre culturas distintas produz formas de interculturalidade, a relação entre sistemas diferentes produz formas de intercientificidade" (LITTLE, 2002, p. 39-40). Já a etnometodologia "[...] propõe a suspensão de valores e (pré-) conceitos do pesquisador para a obtenção de uma compreensão profunda das lógicas e estruturas internas de determinada sociedade" (COULON, 1995 apud LITTLE, 2002)", e a etnoecologia "[...] pode ser definida como o estudo etnográfico e comparativo de sistemas específicos que um grupo humano utiliza na interação com seu meio biofísico e social" (LITTLE, 2002, p. 40).

De posse dessas noções, Little (2002) propõe uma nova ação indigenista ${ }^{9}$, de modo que houvesse apropriação mútua, entre indígenas e não indígenas, das diferentes concepções de mundo natural, práticas medicinais e tecnologias adaptativas, entre outros temas a serem tratados em "[...] um conjunto de atividades em forma de cursos de aperfeiçoamento, oficinas e seminários direcionados para

9 Indigenismo é a prática estatal e extraestatal dedicada ao relacionamento com os povos indígenas. 
distintos públicos-alvo, práticas que já mostraram alto grau de efetividade na área ambiental" (LITTLE, 2002, p. 42-3).

Com isso o pesquisador tenciona construir um ambiente propício para a produção de conhecimentos e tecnologias localmente efetivos, e com possibilidades de multiplicação, representando os novos sistemas híbridos de adaptação e produção de um subsídio básico para qualquer programa de desenvolvimento verdadeiramente sustentável (LITTLE, 2002, p. 44-5).

Abordagens complexas, que já perduram mais de três décadas, mas estão longe de fazer parte de um senso mais generalizado sobre as potencialidades dos povos indígenas quanto ao próprio desenvolvimento, e quanto à contribuição com o desenvolvimento da sociedade envolvente, com troca simétrica de conteúdos tecnológicos e visões de mundo.

Nesse sentido, possivelmente vislumbrando a multiplicidade do pensamento indígena sobre os temas economia, organização social e reprodução física e cultural, foi que a Convenção n. 169, da Organização Internacional do Trabalho (OIT, 2011), ao tratar dos povos indígenas e tribais em todo o mundo, previu no seu artigo 7, o direito dos povos indígenas em definirem suas prioridades de desenvolvimento:

Os povos interessados terão o direito de definir suas próprias prioridades no processo de desenvolvimento na medida em que afete sua vida, crenças, instituições, bem-estar espiritual e as terras que ocupam ou usam para outros fins, e de controlar, na maior medida possível, seu próprio desenvolvimento econômico, social e cultural. Além disso, eles participarão da formulação, implementação e avaliação de planos e programas de desenvolvimento nacional e regional que possam afetá-los diretamente. (OIT, 2011).

Segundo esse dispositivo do direito internacional, recepcionado pelo Brasil em $2004^{10}$, os povos indígenas além da prerrogativa de serem consultados (artigo 6) para projetos e empreendimentos que incidam sobre seus territórios, também devem possuir autonomia em decidirem por suas prioridades próprias, quanto ao desenvolvimento econômico, social e cultural de suas comunidades e de seus territórios.

${ }^{10}$ Decreto n. 5.051/2004. 
No âmbito da América Latina, porém, a legislação interna que mais contribui para tornar factível essa legislação internacional é a equatoriana ${ }^{11}$, porquanto desde 1998, passando por uma reforma constitucional em setembro de 2008, a carta do Equador incorporou uma visão biocêntrica do direito (e não mais antropocêntrica), introduzindo no ordenamento o conceito de "direitos da natureza". Em seu preâmbulo celebra "[...] a natureza, a Pacha Mama, de que somos parte e que é vital para nossa existência" (EQUADOR, 2008).

Boaventura de Sousa Santos, em comentário à edição brasileira do livro de Alberto Acosta (2016, n.p.), equatoriano que foi um dos responsáveis por colocar a perspectiva indígena na Constituição daquele país, pondera:

[...] ao incorporar o Buen Vivir à sua Constituição, o Equador saiu da jaula da dependência e do subdesenvolvimento político e ideológico: afirmou-se como uma nação em pé de igualdade com as demais, decidida a compartilhar as causas pelas quais vale a pena lutar caso realmente haja futuro.

Acosta (2016, n.p.), de sua vez, relembra:

[...] a partir da década de 1960, especialmente, apareceram posições e visões críticas ao desenvolvimento no terreno econômico, social e, mais tarde, ambiental. A América Latina contribuiu com potentes leituras contestadoras - 0 estruturalismo e a teoria da dependência, por exemplo.

Como vislumbra Santos (apud ACOSTA 2016, n.p.), o debate gira em torno de [...] uma alternativa ao desenvolvimento; como uma dimensão dos Direitos da Natureza; como a matriz de uma nova economia solidária e plural de vocação pós-extrativista e pós-capitalista; e como uma semente que só germinará em um novo tipo de Estado, o Estado plurinacional, que é construído com a participação dos cidadãos, dos povos e das nacionalidades, por meio de diferentes formas de democracia - o que eu chamo "demodiversidade".

No capítulo seguinte serão apresentadas experiências dos povos indígenas nas suas relações com o Estado nacional relativas ao desenvolvimento, assim como

\footnotetext{
${ }^{11}$ Segundo Isabela Figueroa (2006), "A Constituição equatoriana é a mais avançada da América Latina no que se refere ao reconhecimento dos direitos coletivos. Orientada por parâmetros do direito internacional, estabeleceu o Estado multicultural e dedicou um de seus capítulos aos direitos coletivos dos povos indígenas e afro-equatorianos. Sua promulgação, em 1998, abriu novas perspectivas para a reivindicação desses direitos na Justiça e seu desenvolvimento nas leis do país".
} 
a crítica sobre tais iniciativas, as quais, mais das vezes, não levam em consideração o pensamento indígena sobre economia e formas de vida e produção.

\section{A PERSPECTIVA DE DESENVOLVIMENTO ENTRE POVOS INDÍGENAS}

O principal desafio ao que se poderia entender por desenvolvimento entre povos e nos territórios indígenas é o garantir o respeito às instâncias políticas e de direito interno dos indígenas, compreendendo para isso a consulta prévia e informada às populações indígenas nos termos aventados pelo artigo 6으, da Convenção 169 da OIT.

Referida convenção foi entronizada no direito brasileiro pelo Decreto n. 5.054, de 2004, constituindo assim parte do ordenamento interno. Ocorre que as disposições da convenção raramente são levadas em conta na tomada de decisões não sendo raro que os indígenas suscitem falta de consulta a seus interesses perante o Estado e outros partícipes do desenvolvimento nacional quando são projetados empreendimentos, principalmente no campo da infraestrutura, tais como estradas, hidroelétricas e ferrovias.

Relativamente à autonomia na gestão de territórios - os quais em boa parte ainda pendem de ser demarcados - o avanço vem ocorrendo, ainda que a passos lentos. No ano de 2008 foi criado um grupo interministerial encarregado de preparar o decreto regulamentador da Política Nacional de Gestão Ambiental e Territorial em Terras Indígenas (PNGATI). Foram realizadas consultas aos indígenas em todo o País, chegando-se ao Decreto n. 7.747, de 5.6.2012.

A normativa em questão instituiu a referida PNGATI, com o objetivo de garantir e promover a proteção, a recuperação, a conservação e o uso sustentável dos recursos naturais das terras e territórios indígenas, assegurando a integridade do patrimônio indígena, a melhoria da qualidade de vida e as condições plenas de reprodução física e cultural das atuais e futuras gerações dos povos indígenas, respeitando sua autonomia sociocultural.

Constitui, portanto, importante contribuição positivada para a autonomia de gestão que se espera atingir nas terras indígenas, sendo uma de suas diretrizes o protagonismo e autonomia sociocultural dos povos indígenas. Foi prevista a participação indígena na chamada governança da PNGATI, respeitadas as instâncias de representação indígenas e as perspectivas de gênero e geracional. 
Ocorre que sua implementação depende de programas e ações previstos no plano plurianual, nas diretrizes orçamentárias e nos orçamentos anuais, além de outras iniciativas e parcerias. Num quadro de limitação do orçamento federal introduzido pela Emenda Constitucional n. 95, de 2017, o chamado teto de gastos públicos, é possível que as ações do PNGATI se vejam também limitadas, exigindo dos povos indígenas iniciativas próprias, tais como o etnoturismo, a visitação pública de suas terras e a comercialização de excedentes produtivos, a fim de dar conta da gestão autônoma esperada.

Entretanto, nem sempre foram praticadas propostas como essa descrita acima, ainda que atualmente, não tenha recursos e dependa do Governo Federal para sua efetivação e continuidade. O mais comum, nos últimos anos, são ações pontuais, algumas eleitoreiras, geralmente pensadas em gabinetes, como respostas às supostas demandas das comunidades indígenas. Nas últimas duas décadas, várias foram as iniciativas dos governos e políticos do Estado de Mato Grosso do Sul, com emendas parlamentares e Projetos de incentivo à agricultura familiar que chegaram até algumas aldeias. O formato geralmente é igual para todo o Estado, contemplando a agricultura familiar nos assentamentos, comunidades quilombolas e aldeias indígenas, com ênfase na agricultura mecanizada, pois o centro do projeto é a entrega de um trator e seus complementos (patrulha mecanizada).

Diante da entrega de equipamentos, combustível e sementes, as lideranças (caciques das aldeias) prontamente aceitam tais "presentes" que, no entanto, não conseguem fazer frente às demandas dessas comunidades, pois trata-se de iniciativa realizada sem a devida consulta às comunidades, e com foco em outra lógica de produção, voltada para a monocultura, em total desrespeito às lógicas centenárias dos povos indígenas em sua relação com o ambiente e a produção de alimentos.

Quando em 2004/5 o Governo do Estado de Mato Grosso do Sul, com recursos na ordem de 5 milhões de reais, implantou o Programa Fome Zero Indígena, um dos eixos estruturantes era a agricultura nas aldeias. Apesar da consultoria antropológica e todos os eventos propostos à época, de formação dos agentes públicos, o que se viu, foi um total descompasso, entre os tempos das aldeias e das roças (tempo de preparar a terra, tempo da chuva, tempo para semear e colher) e suas cosmologias, e o tempo da burocracia dos gabinetes, sobretudo quando cada ação/gasto precisava de licitação. Primeiro chegou o calcário, em grandes 
quantidades, mas então, descobriu-se que nas aldeias faltava equipamentos apropriados para sua aplicação e, sobretudo, faltava combustível.

Em seguida veio a semente, mas o calcário ainda não havia sido aplicado e com as chuvas, mais da metade ficou inviável para o uso. Quando finalmente havia todas as condições para iniciar o processo de preparo da terra e plantio da semente, já havia passado o tempo propício para a plantação, com flagrante prejuízo de todo o processo, mesmo dentro da mentalidade do Estado: agricultura mecanizada e de monocultura.

Temos ainda outros exemplos, mais recentes, como a tentativa voluntária de estimular o plantio de erva-mate em aldeia Guarani no sul de Mato Grosso do Sul. Através de doação das mudas, a orientação foi procurar famílias voluntárias que se dispusessem a iniciar a prática de plantio. Como a família da liderança se apresentou desde o início, outras ficaram inibidas em participar e a primeira experiência acabou sendo apenas com esse grupo macro familiar e com menos da metade da meta proposta de plantio.

Quando fomos perguntar para um grupo de famílias dissidentes, tidos como "tradicionais", porque não aceitaram um projeto "tão bom", responderam: "Ninguém come a erva-mate; o que a gente quer é rama de mandioca para plantar; daqui a poucos meses temos comida". A erva-mate, planta tradicional na cultura guarani começa a produzir, após cinco anos em média.

Outras experiências havidas após 1988, enfrentaram problemas parecidos, porquanto o modelo apresentado pelas agências governamentais, esbarra na forma de organização social das sociedades indígenas.

Na Reserva Indígena de Dourados (RID), em Mato Grosso do Sul'12, o associativismo é exemplo de um modelo não afeito à organização social das etnias, mas que gerou a criação de vários desses organismos em determinada época,

\footnotetext{
12 "A Reserva Indígena de Dourados (RID) foi criada no início do Século XX, pelo Decreto n. 401, de 03 de setembro de 1917 com uma área de 3.600 hectares, de um tamanho aproximado ao das outras sete reservas, na região do sul do Estado de Mato Grosso. No entanto, durante a demarcação o território da reserva ficou com 3.539 ha. como consta no título registrado em 26/11/1965 no Cartório de Registro de Imóveis, na Delegacia Especial de Terras e Colonização de Campo Grande. A medida atual, segundo a FUNAI, é de 3474,59 ha (BRASIL, 2018). A região fazia parte do município de Ponta Porã, local historicamente marcado pela extração da erva mate, quando o inspetor do SPI, Major Nicolau Horta Barbosa começou a demarcar a área (TROQUEZ, 2007)" (ALMEIDA; MOURA, 2019, p. 229).
} 
por conta de incentivos governamentais, como relatam Almeida e Moura (2019, p. 232):

[...] as primeiras associações formadas nas aldeias estavam interessadas em acessar recursos para a agricultura, como por exemplo, o PRONAF (Programa Nacional de Fortalecimento da Agricultura Familiar) e depois do ano 2003 o Programa Carteira Indígena, que foi o principal estimulador de formação das associações em Dourados como será apresentado nos próximos itens. O Programa Carteira Indígena foi desenvolvido em parceria entre o Ministério do Desenvolvimento Social e Combate à Fome - MDS e o Ministério do Meio Ambiente-MMA. Consistiu em financiar projetos sustentáveis para as populações indígenas. A relevância dessa ação para a formação de associações é que a Carteira Indígena foi um dos primeiros projetos que visava repassar os recursos diretamente para as organizações indígenas regulamentadas. No ano de 2005 suas atividades foram intensificadas na região sul do Mato Grosso do Sul, e consequentemente na Reserva de Dourados, devido à repercussão internacional das denúncias da mortalidade infantil Guarani e Kaiowá.

A gestão mediante critérios afastados das relações sociais e de poder dentro das comunidades ocasionaram, entretanto, os estranhamentos relatados pelas pesquisadoras, concernentes aos Guarani e Kaiowá. A organização social dessas duas etnias prevê a existência de fogos domésticos (família nuclear) e de parentelas (família extensa), havendo "[...] uma obrigação da liderança em distribuir recursos entre os membros do fogo primeiramente, e, depois para a parentela" (ALMEIDA; MOURA, 2019, p. 237). A obrigação social do líder da parentela acaba por afetar a maneira como os recursos trazidos para uma associação são alocados e empregados.

Um exemplo, foi citado pela pesquisadora Liliany Passos (2007), em relação a uma liderança da aldeia Jaguapiru. Este indivíduo, que fazia parte da associação A, num determinado ano recebeu verba para desenvolver certa atividade coletiva (produzir quatro mil CDs). Quando Passos esteve em campo ouviu acusações de que essa liderança teria gasto a verba com parentes e havia deixado a associação A de lado e estava constituindo a associação B (PASSOS, 2007). Sobre esse tema, que gera incômodos, inclusive nos representantes de instituições, Levi Pereira (2004) comenta que: "o fato de as comunidades estarem organizadas em parentelas cria uma série de problemas para a implementação de programas sociais, principalmente devido à incompreensão dos agentes indigenistas. A atuação das instituições normalmente depende de representantes colocados como interlocutores entre a comunidade e as iniciativas externas. Os índios colocados na posição de representantes legais 
da comunidade vivem o dilema de ficarem divididos entre a lealdade ao grupo de parentesco - que se sobrepõe a qualquer outra lealdade, administrativa ou burocrática - e a pressão para exercerem o cargo a eles atribuído com a postulada de equanimidade administrativa. Atender aos interesses dos parentes é um dever moral para a pessoa no sistema social kaiowá, mesmo que isto implique em dificuldades no trato com os administradores ou outras parentelas (PEREIRA, 2004 apud ALMEIDA; MOURA, 2019, p. 237-8).

Este é apenas um dos exemplos, dentre muitos, em que há a confrontação do modo de ser e se organizar indígena - no caso, ser Guarani ou Kaiowá - e as formas institucionais da sociedade não indígena, para acessar recursos materiais (no caso, fomento em dinheiro), produzir bens e fazer a circulação de mercadorias.

Ao terem acesso aos recursos dos brancos, os indígenas empregam o seu modo de pensar para deliberar o que fazer com eles, acabando por criar, muitas vezes, conflitos internos nas comunidades, como no caso da experiência associativista na RID e os recursos da carteira indígena.

Uma associação formatada nos moldes do direito civil brasileiro carece de significado maior para os indígenas que, de início, convencem-se da boa ideia trazida pelos brancos, até mesmo porque envolve recursos financeiros, valorizados na sociedade não indígena. Ao acessar tais recursos, porém, não há garantia de que serão empregados do modo como os brancos idealizaram, prevalecendo as relações sociais e vínculos de lealdade modulados segundo a cultura tradicional.

Iniciativas anteriores, quando não haviam as mesmas estruturas observadas contemporaneamente - disciplinas próprias nas universidades e pesquisa, por exemplo - também esbarraram em dificuldades de diálogo intercultural, significando a complexidade da interface entre a noção ocidental de desenvolvimento e as práticas produtivas indígenas.

Thomaz de Almeida (2001), a partir de projeto Kaiowá-Ñandeva, ou PKN (1973-1981), protagonizado pelos Guarani e Kaiowá de Mato Grosso do Sul, realizou extenso trabalho de escrita antropológica sobre a compreensão desses povos relacionada com o etnodesenvolvimento. O projeto previa que os GuaraniÑandeva e Kaiowá plantassem roças comunitárias aproveitando um influxo oficial realizado por agências governamentais, com ajuda financeira internacional. A ideia era utilizar-se do conceito de etnodesenvolvimento, superando com isso a 
relação estabelecida pelo indigenismo oficial da época com os povos indígenas, e suas formas próprias de desenvolvimento:

[...] negando o raciocínio manifestado no binômio "integração-desenvolvimento", que até então norteava o indigenismo oficial, e propondo outro binômio, de "cultura-etnodesenvolvimento" (STAVENHAGEM, 1985 apud THOMAZ DE ALMEIDA, 2011, p. 185).

Uma das conclusões apresentadas dimensiona a lógica peculiar que atravessa as relações dos Kaiowá e Ñandeva com o objeto econômico:

Nas experiências do Projeto Kaiowá-Ñandeva, observou-se essa lógica peculiar, diferente da racionalidade capitalista, na utilização da terra e do campo dedicado ao trabalho. Isso não deve ser interpretado como um gerador de conflitos ou como prova da 'incapacidade' dos indígenas de administrar uma criação de porcos ou um cafezal, como considerou Schaden (1974:65). Não se trata de saber administrar, mas de desejar fazê-lo, levando em conta as decorrências e implicações dessas e de outras atividades. Os Kaiowá e Ñandeva não parecem querer realizar essa administração. Seu modo de realizar os cálculos econômicos, sua concepção de produção e consumo, seus hábitos alimentares e sua cultura não comportam a institucionalização de modelos que consideram que lhes são alheios. (ALMEIDA, 2001, p. 190).

Entretanto, outras experiências, essas mais exitosas, demonstram que é possível aos indígenas recriarem em tempos atuais as antigas práticas produtivas, com apoio em técnicas próprias. Essas técnicas, porém, passaram por um processo de mediação, e foram acolhidas nas instâncias não indígenas, tais como universidades e instituições de pesquisa, com foco na agroecologia.

Um exemplo bem-sucedido pode ser apontado na experiência agroecológica da aldeia Mãe Terra, dos Terena, de Mato Grosso do Sul. A experiência ficou marcada pela diversidade em relação aos paradigmas agrícolas não indígenas, uma vez que

[...] essa diferença aparece plasticamente, descrita no cotidiano da agricultura em uma aldeia terena comum, como um respeito pelos ritmos de cada espécie, o que implica uma sensação de interação que ocorre entre água, plantas, solo e animais. Os Terena não podem ser reduzidos ao horário do dia de trabalho, ou seja, o horário do relógio. Em vez disso, diz respeito a seguimentos sistemáticos de ritmos específicos do meio ambiente, cujo ritmo é definido pelo "dono da floresta", que às vezes se mistura com a própria floresta, às vezes recebe um rosto cristianizado. (MACIEL et al., 2019, p. 869). 
Apanha-se dessa breve exemplificação que os sistemas produtivos e de distribuição de recursos não indígenas são inservíveis para promover o que chamamos de "desenvolvimento". Podem, no entanto, contribuir com suas economias, desde que não se aguarde por resultados estritamente planejados. Ainda que se consulte, e haja a aceitação da comunidade, o desencadear do projeto pode desaguar em um resultado não esperado, em razão das inúmeras variáveis e fatores imponderáveis, relacionados com a baixa qualidade do diálogo intercultural, ou ausência de acolhimento dos pressupostos próprios do pensamento indígena em cada iniciativa.

\section{CONSIDERAÇÕES FINAIS}

Conclui-se, através dos exemplos e da revisão bibliográfica realizada, que o conceito de desenvolvimento sustentável ainda não contempla suficientemente o pensamento indígena sobre processos produtivos, consumo, circulação de bens e bem-estar. No entanto, em razão das suas peculiaridades culturais, os povos indígenas são os que mais se aproximam desse conceito, uma vez que, raramente ou nunca, chegam ao ponto do esgotamento dos recursos naturais. Não se percebe que haja a provocação deliberada de danos ambientais, ao tempo em que os cuidados conservacionistas com a natureza são observados por quantos se debruçam sobre a avaliação ambiental dos espaços habitados pelos indígenas, quais sejam, as reservas, aldeias e terras indígenas.

O etnodesenvolvimento ficou restrito, até o presente, a um locus próprio dentro das ciências sociais, não sendo considerado nas ciências econômicas onde não se acha menção à sua existência enquanto teorização do desenvolvimento entre os povos indígenas. De sua vez, a noção de desenvolvimento sustentável vem sendo questionada dentro da teoria crítica, e dos estudos do pós-desenvolvimento, uma vez que aparenta não ter podido superar a contradição entre uma economia voltada para o lucro (capitalista) e a necessidade de se poupar os recursos naturais para as gerações futuras.

\section{REFERÊNCIAS}

ACOSTA, Alberto. O bem viver: uma oportunidade para imaginar outros mundos. São Paulo: Autonomia Literária/Elefante, 2016. 
AGUILERA URQUIZA, Antonio H. Antropologia e história dos povos indígenas em Mato Grosso do Sul. Campo Grande: Editora UFMS, 2016.

ALMEIDA, Ellen Cristina; MOURA, Noêmia dos Santos Pereira. Associativismo na reserva indígena de dourados: um destaque para a associação de mulheres indígenas. In: MOTA, Juliana Grasiéli Bueno; CAVALCANTE, Thiago Leandro Vieira (Org.). Reserva indígena de Dourados: histórias e desafios contemporâneos. São Leopoldo: Karywa, 2019. 285 p.

ALMEIDA, Rubem Ferreira Thomaz. Do desenvolvimento comunitário à mobilização política: o projeto Kaiowa-Ñandeva como experiência antropológica. Rio de Janeiro: Contra Capa Livraria, 2001.

AZANHA, Gilberto. Etnodesenvolvimento, mercado e mecanismos de fomento: possibilidades de desenvolvimento sustentado para as sociedades indígenas no Brasil. In: SOUZA LIMA, Antonio Carlos; BARROSO-HOFFMAN, Maria (Org.). Etnodesenvolvimento e políticas públicas: bases para uma nova política indigenista. Rio de Janeiro: Contra Capa Livraria, 2002. p. 29-37.

BRASIL. Assembleia Nacional Constituinte. Constituição da República Federativa do Brasil. Brasília-DF, 1988.

CHAPARRO, Yan Leite; HARA, Joaquim Adiala; MACIEL, Josemar de Campos. Uma conversa sobre atravessamentos e pacificações Avá Guarani/Ñandeva de Porto Lindo (Jakarey) Yvy Katu sobre a invenção branca de desenvolvimento. Revista Ñanduty, [s.I.], v. 7, n. 10, p. 217-32, ago. 2019.

EQUADOR. Poder Legislativo. Constituição do Equador. Quito, 2008.

FIGUEROA, Isabela. Povos indígenas versus petrolíferas: controle constitucional na resistência. Sur - Revista Internacional de Direitos Humanos, São Paulo, v. 3, n. 4, p. 4879, 2006.

FREITAS, Tanise Dias; CASSOL, Abel; CONCEIÇÃO, Ariane Fernandes; NIERDELE, Paulo André. Sen e o Desenvolvimento como Liberdade. In: NIEDERLE, Paulo André; RADOMSKY, Guilherme Francisco (Org.). Introdução às teorias do desenvolvimento. Porto Alegre: UFRGS, 2016. p. 50-62.

FREITAS, Gabriela Rocha; CRUZ, Mailane Junkes Raizer; RADOMSKY, Guilherme Francisco. Pós-desenvolvimento: a desconstrução do desenvolvimento. In: NIEDERLE, Paulo André; RADOMSKY, Guilherme Francisco (Org.). Introdução às teorias do desenvolvimento. Porto Alegre: UFRGS, 2016. p. 92-8. 
GÓMEZ, Jorge Montenegro. Por uma crítica ao desenvolvimento sustentável. Pegada, Presidente Prudente, v. 3, n. 1, [n. p.], 2002. Disponível em: https://revista.fct.unesp. br/index.php/pegada/article/view/798. Acesso em: 18 set. 2020. doi: https://doi. org/10.33026/peg.v3i1

IBGE. Censo Brasileiro de 2010. IBGE, Rio de Janeiro, 2012. Disponível em: https:// censo2010.ibge.gov.br/. Acesso em: 1 ago. 2021.

LATOUCHE, Serge. Pequeno tratado do decrescimento sereno. Tradução de Cláudia Berliner. São Paulo: Martins Fontes, 2009.

LATOUCHE, Serge. O desenvolvimento é insustentável. In: CARDENOS IHU EM FORMAÇÃO. Sociedade Sustentável. Instituto Humanista Unisinos, São Leopoldo, v. 2, n. 7, p. 5-10, 2006.

LITTLE, Paul E. Etnoecologia e direitos dos povos: elementos de uma nova ação indigenista. In: SOUZA LIMA, Antonio Carlos; BARROSO-HOFFMAN, Maria (Org.). Etnodesenvolvimento e políticas públicas: bases para uma nova política indigenista. Rio de Janeiro: Contra Capa Livraria, 2002. p. 39-47.

MACIEL, Josemar de Campos; SURIAN, Alessio; BRAHMLLARI, Estela; TARASCONI, Bibiane Ferreira; ANTONIO, Leosmar. Terena agriculture and life-system: a speech and beyond. Interações, Campo Grande, v. 20, n. 3, p. 861-77, jul./set. 2019.

OLIVEIRA, Lucas Rebello; MEDEIROS, Raffaela Martins; TERRA, Pedro de Bragança; QUELHA, Osvaldo Luiz Gonçalves. Sustentabilidade: da evolução dos conceitos à implementação como estratégia nas organizações. Produção, Niterói, v. 22, n. 1, p. 7082, jan./fev. 2012.

ORGANIZAÇÃO INTERNACIONAL DO TRABALHO [OIT]. Convenção n. 169 sobre povos indígenas e tribais e resolução referente à ação da OIT. Brasília: OIT, 2011.

ORGANIZAÇÃO DAS NAÇÕES UNIDAS [ONU]. Agenda 21. Rio de Janeiro: ONU, 1989.

ORGANIZAÇÃO DAS NAÇÕES UNIDAS [ONU]. Comissão Mundial sobre Meio Ambiente e Desenvolvimento. Nosso futuro comum. [s.l.], 1987.

RAMID, João; RIBEIRO, Antônio. Declaração do Rio de Janeiro: a conferência das Nações Unidas sobre meio ambiente e desenvolvimento. Estudos Avançados, São Paulo, v. 6, n. 15, 1992.

REDE DE COOPERAÇÃO AMAZÔNICA [RCA]. Protocolo de consulta e consentimento Wajãpi. 2. ed. Macapá: RCA: 2015. 
SANTOS, Elinaldo Leal; SANTOS, Vitor Braga; SANTOS, Reginaldo Souza; BRAGA, Alexandra Maria da Silva. Desenvolvimento: um conceito multidimensional. Desenvolvimento Regional em Debate, Mafra, v. 2, n. 1, jul. 2012.

SEN, Amartya. Desenvolvimento como liberdade. São Paulo: Companhia das Letras, 2000.

SOUZA LIMA, Antonio Carlos. Povos indígenas no Brasil contemporâneo: de tutelados a "organizados"? In: SOUSA, Cássio Noronha Inglez; ALMEIDA, Fábio Vaz Ribeiro; LIMA, Antonio Carlos de Souza; MATOS, Maria Helena Ortolan (Org.). Povos indígenas: projetos e desenvolvimento. Brasília: Paralelo 15, 2010. p. 15-50. v. 2.

VARGAS, Felipe; CERPA, Yara Paulina; RADOMSKY, Guilherme Francisco Waterloo. Desenvolvimento sustentável: introdução histórica e perspectiva teóricas. In: NIEDERLE, Paulo André; RADOMSKY, Guilherme Francisco Waterloo (Org.). Introdução às teorias do desenvolvimento. Porto Alegre: UFRGS, 2016. p. 99-107.

VIZEU, Fabio; MENEGHETTI, Francis Kanashiro; SEIFERT, Rene Eugenio. Por uma crítica ao conceito de desenvolvimento sustentável. Caderno EBAPE, Rio de Janeiro, v. 10, n. 3, p. 569-83, set. 2012.

\section{Sobre os autores:}

Adriana de Oliveira Rocha: Mestre em Direito pela Universidade Federal de Mato Grosso do Sul (UFMS). Graduação em Direito pelas Faculdades Unidas Católicas de Mato Grosso (FUCMAT). Área de concentração em Direitos Humanos na UFMS. E-mail: adrianasvbcg@hotmail.com, ORCID: https://orcid.org/0000-0001-8980-0968

Antônio Hilário Aguilera Urquiza: Doutor em Antropologia pela Universidade de Salamanca (USAL), Espanha. Mestre em Educação pela Universidade Federal de Mato Grosso (UFMT). Graduação em Educação pela Universidade de Cuiabá (UNIC). Professor associado na Universidade Federal de Mato Grosso do Sul (UFMS); de pós-graduação em Antropologia Social e em Direito na UFMS. Líder do grupo de pesquisa Antropologia, Direitos Humanos e Povos Tradicionais. Bolsista PQ2. E-mail: hilarioaguilera@gmail.com, ORCID: https://orcid.org/0000-0002-3375-8630

Recebido em: 11/11/2020

Aprovado para publicação em: 16/12/2020 